\title{
FERMENTAÇÃO ALCOÓLICA DE SUBSTRATO AMILÁCEO HIDROLISADO ENRIQUECIDO COM MELAÇO DE CANA
}

\author{
Alcoholic fermentation of starchy hidrolisated substrate with sugar cane residue
}

Lizandra Bringhenti' ${ }^{1}$ Claudio Cabello ${ }^{2}$, Luiz Henrique Urbano ${ }^{3}$

\begin{abstract}
RESUMO
A farinha constitui um dos principais produtos da mandioca, e seu uso é muito difundido em todo o País. Durante o processamento da mandioca para a obtenção da farinha é gerado um resíduo sólido proveniente da decantação da manipueira, o qual é composto essencialmente por amido. Diante da importância do aproveitamento de resíduos agroindústrias para a geração de energia e como fonte de renda para as empresas, com este trabalho objetivou-se avaliar o efeito da adição de melaço (resíduo da produção de açúcar de cana) no preparo de soluções de amido para hidrólise enzimática e fermentação alcoólica. Os resultados obtidos demonstraram que a adição de melaço no resíduo amiláceo inicial em doses a partir de $10 \%$ levou a um aumento no teor de açúcares no mosto promovendo um aumento de $112 \%$ na produção de etanol, em relação ao substrato sem aditivo. Contudo, a seleção de leveduras adaptadas ao substrato faz-se necessária para um melhor rendimento em etanol.
\end{abstract}

Termos de indexação: Resíduo amiláceo, melaço, fermentação alcoólica.

\begin{abstract}
The cassava flour is a one of most important commercial product of cassava industries. During the cassava flour processing is obtained a solid residue from 'manipueira' decantation, which is characterized by high level of starch. Due the importance of the residue usage as energy source and income product for industries this work had as purpose to evaluate the addition of sugarcane residue (melaço) as supplementary raw material in hydrolysis and fermentation process of cassava starch solution for ethanol production. The results showed that the increase of sugarcane residue percentage in initial solution (>10\%) caused the increase of sugar concentration in must and high ethanol yield (increase of $112 \%$ when compared with substrate the without sugarcane residue). The yeast selection and substrate adaptation is necessary for increase of ethanol production from cassava starch residue.
\end{abstract}

Index terms: Starch residue, sugarcane residue and alcoholic fermentation.

\section{(Recebido em 2 de agosto de 2004 e aprovado em 11 de setembro de 2006)}

\section{INTRODUÇÃO}

Graças à vasta biodiversidade encontrada em seu território, o Brasil dispõe de uma grande variedade de resíduos agrícolas e agroindustriais, cujo bioprocessamento é de grande interesse econômico e social. É importante fomentar a demonstração das vantagens existentes e encorajar o investimento no desenvolvimento de novas tecnologias para se obter ganho energético a partir de recursos renováveis, que são produzidos em grande quantidade no País.

As agroindústrias que fabricam farinha de mandioca no Brasil apresentam variados níveis tecnológicos em seus processos produtivos, os quais refletem tanto na qualidade do produto quanto na quantidade e composição dos resíduos gerados.

Durante o processo de fabricação da farinha de mandioca na etapa de prensagem é gerado um resíduo líquido denominado manipueira, descrito como a água de constituição das raízes de mandioca. Este resíduo passa por um processo de decantação em sistema de labirinto ficando depositado o amido residual, o qual apresenta-se como substrato potencial para processos fermentativos.

A produção de álcool fino a partir dos resíduos da indústria da mandioca acena como uma alternativa para transformar o resíduo amiláceo em co-produto, gerando não só receita para a indústria como todos os benefícios mercadológicos de uma indústria limpa. Aliado a crescente evolução tecnológica, hoje é necessário reavaliar antigos projetos, outrora descartados pela sua inviabilidade econômica.

O álcool fino é matéria-prima para as indústrias de bebidas, de perfumarias, produtos farmacêuticos e, eventualmente indústrias químicas e alimentícias. $\mathrm{Na}$ indústria de bebidas o álcool fino é usado principalmente na correção do teor alcóolico de vinhos, fabricação de vodca, licores e aperitivos. $\mathrm{Na}$ indústria farmacêutica é usado na extração de princípios ativos naturais, elaboração de perfumes e como diluente.

'Doutoranda Energia na Agricultura, FCA/UNESP - Fazenda Experimental Lageado s/n - Cx. P. 237 - Botucatu, SP.

${ }^{2}$ Diretor CERAT/UNESP - Fazenda Experimental Lageado s/n - Cx. P. 237 - Botucatu, SP - dircerat@fca.unesp.br

${ }^{3}$ Técnico em Química, CERAT/UNESP - Fazenda Experimental Lageado s/n - Cx. P. 237 - Botucatu, SP. 
Os amidos de mandioca apresentam pequenas concentrações de matérias graxas e proteínas e, portanto o seu hidrolisado necessita ser aditivado com outros materiais para torná-lo adequado à fermentação alcóolica. O melaço originário da fabricação de açúcar de cana possui oligoelementos, vitaminas e precursores, entre outros, que tornam este material de baixo custo interessante como aditivo, além dos altos teores de açúcares fermentescíveis. Aliado a isso, experimentos realizados por Najafpour \& Shan-Poi (2003) demonstraram um aumento da quantidade de açúcares fermentescíveis em ensaios de hidrólise enzimática de melaço de cana por conta da concentração de amidos presentes na cana de açúcar.

Este trabalho teve como objetivo avaliar a fermentabilidade do hidrolisado obtido a partir misturas de amido residuário da fabricação de farinha de mandioca enriquecido com diferentes teores de melaço.

\section{MATERIAL E MÉTODOS}

\section{Material}

$\mathrm{O}$ amido residuário do processamento de farinha de mandioca foi doado pela empresa Plaza Indústria e Comércio Ltda, situada em Santa Maria da Serra-SP.

O melaço de cana-de-açúcar obtido no processo de cristalização da sacarose foi concedido pela Usina de Açúcar da Barra, localizada na cidade de Barra Bonita-SP.

Durante o processo de hidrólise foram utilizadas uma $\alpha$-amilase -Termamyl 120L (Novo Nordisk), na primeira fase da hidrólise e outras duas enzimas para a hidrólise total a amiloglucosidase (AMG 300L) da NOVO NORDISK, e pululanase (PROMOZIME) da NOVO NORDISK.

A cepa utilizada foi a Saccharomyces cerevisiae, cedida pelo CPQBA/UNICAMP, mantida em meio PDA.

\section{Preparação e padronização dos substratos}

Uma suspensão a $10 \%$ do resíduo amiláceo foi préhidrolisada com $\alpha$-amilase Termamyl 120L, na proporção de $1,5 \mathrm{KMU} / \mathrm{g}$ de amido seco, na temperatura de $90^{\circ} \mathrm{C}$, por 2h. A quantidade total de carbono orgânico (TOC) do préhidrolisado obtido foi medida. Em separado, foi preparada uma solução de mel residual e água e a mesma foi padronizada até obter-se a mesma quantidade de carbono orgânico contida no hidrolisado.

Em erlenmeyers de $1000 \mathrm{~mL}$ foram adicionadas as seguintes quantidades: $500 \mathrm{~mL}$ de hidrolisado sem adição de melaço, T1 (0\%); $475 \mathrm{~mL}$ de hidrolisado e $25 \mathrm{~mL}$ de sol. melaço residual, T2 (5\%); $450 \mathrm{~mL}$ de hidrolisado e $50 \mathrm{~mL}$ de sol. melaço residual, T3 (10\%); $425 \mathrm{~mL}$ de hidrolisado e 75
$\mathrm{mL}$ de sol. melaço residual, T4 (15\%); $400 \mathrm{~mL}$ de hidrolisado e $100 \mathrm{~mL}$ de melaço residual, T5 (20\%) e $500 \mathrm{~mL}$ de solução de melaço, T6 (100\%). Deste modo, cada solução produzida apresentava a mesma concentração de carbono orgânico com diferentes concentrações de aditivo.

\section{Hidrólise dos tratamentos}

Para a hidrólise dos tratamentos anteriormente preparados com amido residual da produção de farinha de mandioca acrescido de melaço residuário, foi utilizada a metodologia descrita por Cabello (1995). Em cada um dos erlenmeyers foram adicionadas outras duas enzimas, $280 \mu \mathrm{L}$ de amiloglucosidase, e $50 \mu \mathrm{L}$ de pululanase, para realizar a hidrólise total do substrato. A solução foi tamponada com tampão acetato para $\mathrm{pH}$ 4,8 e mantida em agitação a $60{ }^{\circ} \mathrm{C}$ por $72 \mathrm{~h}$. Decorrido este tempo elevou-se o pH para 8,5 com adição de $\mathrm{NaOH}(1 \mathrm{~N})$.

\section{Preparação do inóculo}

A cepa utilizada foi a Saccharomyces cerevisiae, mantida em meio PDA.

Preparou-se um meio YM para desenvolvimento e estoque da levedura utilizando-se $3 \mathrm{~g}$ de extrato de levedura, $3 \mathrm{~g}$ de extrato de malte, $5 \mathrm{~g}$ de peptona, $10 \mathrm{~g}$ de dextrose, $20 \mathrm{~g}$ de ágar e água destilada em quantidade suficiente para um litro. Verteu-se $3 \mathrm{~mL}$ de meio em tubos de ensaio, posteriormente tampou-se com algodão e esterilizou-se em autoclave a $121^{\circ} \mathrm{C}$ por $15 \mathrm{~min}$. Após o resfriamento dos tubos de ensaio inoculou-se a levedura mantendo-se os tubos por $24 \mathrm{~h}$ em estufa a $30^{\circ} \mathrm{C}$. Estes tubos foram cobertos com glicerol estéril e mantidos sob refrigeração.

A multiplicação para preparo do inóculo foi realizada inoculando-se uma alçada da cultura em $100 \mathrm{~mL}$ de meio YM sem ágar, por $24 \mathrm{~h}$ a $30^{\circ} \mathrm{C}$. Decorrido este período, os tubos foram centrifugados a $1500 \mathrm{rpm}$ por 5 minutos e a massa de levedura decantada foi novamente inoculada num erlenmeyer contendo $500 \mathrm{~mL}$ de meio YM permanecendo por $24 \mathrm{~h}$ a $30^{\circ} \mathrm{C}$.

\section{Fermentação das soluções}

As soluções preparadas e hidrolisadas foram inoculadas com $1 \mathrm{~mL}$ de solução contendo a levedura, permanecendo em agitação constante a $37^{\circ} \mathrm{C}$ por $28 \mathrm{~h}$.

O consumo de açúcares durante o processo fermentativo dos diferentes tratamentos foi avaliado por cromatografia (HPLC), em diferentes intervalos de tempo.

\section{Perfil cromatográfico}

Para as análises do perfil cromatográfico antes e durante a fermentação uma amostra de $10 \mathrm{~mL}$ de cada 
tratamento nos diferentes tempos foi centrifugada a 12000 rpm durante 8 min., em seguida filtrada em membrana PVDF (difluoreto de polivinilideno) 0,22ìm, de $13 \mathrm{~mm}$ de diâmetro, hidrofílica, sob vácuo. O tempo de corrida foi de $35 \mathrm{~min}$. com temperatura de $65^{\circ} \mathrm{C}$ e a fase móvel utilizada foi ácido sulfúrico $0,005 \mathrm{M}$. Foram determinadas as concentrações de sacarose, frutose, glicose e álcool em cada amostra.

\section{Análise dos dados}

Os resultados obtidos nas determinações dos teores de açúcares por cromatografia nas soluções antes e após hidrólise, bem como o teor de açúcares no vinho e o consumo de açúcares nos diferentes tratamentos, foram submetidos à análise estatística, sendo realizada a análise de variância pelo teste $\mathrm{F}$ e as comparações das médias pelo teste de Tukey ao nível de $5 \%$ de probabilidade (CAMPOS, 1984).

\section{RESULTADOS E DISCUSSÃO}

A determinação dos açúcares nos diferentes tratamentos mostraram diferenças significativas entre os tratamentos, bem como entre a concentração média de açúcares antes e após o processo de hidrólise enzimática. Observou-se aumento dos açúcares fermentescíveis com o aumento da concentração de melaço, não ocorrendo diferença significativa entre os tratamentos com 10, 15 e $20 \%$ de melaço antes da hidrólise. Após a hidrólise ocorreu aumento dos açúcares nas soluções evidenciando a atuação das enzimas amilolíticas tanto no amido originário do resíduo da mandioca quanto dos amidos originários do melaço (Tabela 1).

A partir da concentração inicial de açúcares nas amostras foi calculada a porcentagem de conversão destes açúcares no processo fermentativo (Tabela 2). Observa-se que nos mostos obtidos dos tratamentos com 0 e $5 \%$ de melaço, o consumo de açúcares foi significativamente menor que nos com concentrações a partir de $10 \%$, os quais ficaram próximos de $100 \%$, demonstrando que a adição de melaço na fermentação de suspensões com amido residuário de mandioca leva a um aumento significativo da eficiência de fermentação.

Os resultados obtidos na determinação do teor de álcool no vinho por cromatografia mostrou um aumento deste com o aumento da concentração de melaço nas soluções iniciais, o que confirma os dados obtidos para consumo de açúcares e concentração de açúcares no vinho.

A partir dos resultados obtidos para o volume de etanol no vinho calculou-se o rendimento prático do processo fermentativo em porcentagem de etanol (Figura 1). A adição de $5 \%$ de melaço levou a um aumento de $95,61 \%$ de

TABELA 1 - Valores médios de concentração de açúcares (g/L) fermentescíveis antes e depois da hidrólise enzimática nos diferentes tratamentos.

\begin{tabular}{lcccccc}
\hline & \multicolumn{7}{c}{ Concentração de melaço nas soluções (\%) } \\
Amostragem & 0 & 5 & 10 & 15 & 20 & 100 \\
\hline Antes hidrólise & $100,5 \mathrm{Bc}$ & $110,2 \mathrm{Ac}$ & $143,2 \mathrm{Ab}$ & $147,4 \mathrm{Ab}$ & $151,0 \mathrm{Bb}$ & $219,5 \mathrm{Ba}$ \\
Depois hidrólise & $199,0 \mathrm{Ab}$ & $129,8 \mathrm{Ad}$ & $162,5 \mathrm{Ac}$ & $171,2 \mathrm{Ac}$ & $201,5 \mathrm{Ab}$ & $255,8 \mathrm{Aa}$ \\
\hline
\end{tabular}

* Médias seguidas de mesma letra maiúscula na coluna não diferem entre si em nível de 5\% de significância. Médias seguidas de mesma letra minúscula na linha não diferem entre si em nível de 5\% de significância.

TABELA 2 - Concentração média de açúcares (g/L) no vinho e porcentagem de consumo de açúcares nos diferentes tratamentos.

\begin{tabular}{lcccccc}
\hline & \multicolumn{7}{c}{ Concentração de melaço nas soluções (\%) } \\
Amostras & 0 & 5 & 10 & 15 & 20 & 100 \\
\hline Vinho & $117,3 \mathrm{a}$ & $65,9 \mathrm{a}$ & $7,7 \mathrm{~b}$ & $7,57 \mathrm{~b}$ & $8,80 \mathrm{~b}$ & $0,64 \mathrm{~b}$ \\
Consumo de açúcares $(\%)$ & $41,04 \mathrm{~b}$ & $49,2 \mathrm{~b}$ & $95,26 \mathrm{a}$ & $95,58 \mathrm{a}$ & $95,63 \mathrm{a}$ & $99,75 \mathrm{a}$ \\
\hline
\end{tabular}

\footnotetext{
* Médias seguidas de mesma letra na linha não diferem entre si em nível de 5\% de significância.
} 
rendimento em etanol em relação ao mosto proveniente da hidrólise da solução contendo apenas amido residuário de mandioca. Concentrações superiores de melaço levaram a um aumento linear do rendimento de etanol.

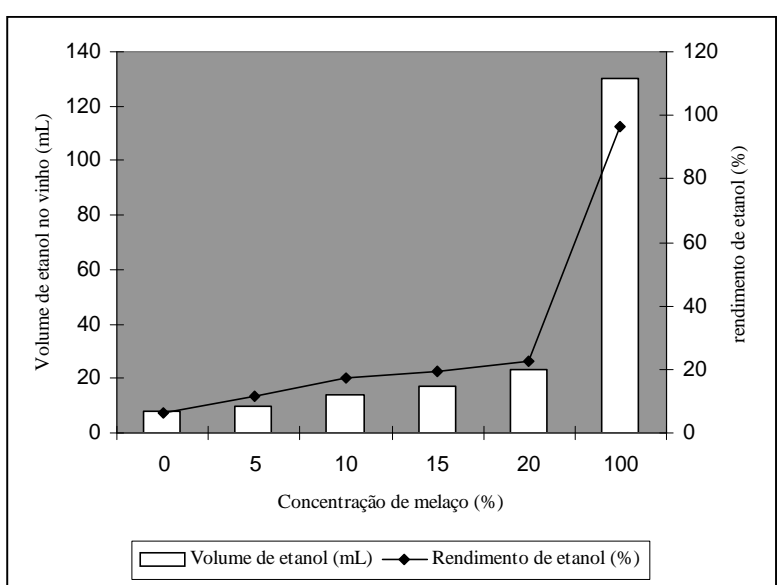

FIGURA 1 - Volume de etanol no vinho e rendimento de etanol de acordo com as concentrações de melaço na solução inicial.

A formulação composta apenas por melaço apresentou uma produção significativa de álcool se comparada com as demais, com um rendimento de etanol de $96,29 \%$. Num processo de fermentação, admite-se que rendimentos entre 43 e $49 \%$ sejam considerados adequados e indicativos de um bom processo de fermentação. Portanto, considerando que os rendimentos obtidos nos tratamentos com a adição de melaço foram inferiores a $23 \%$, uma melhor adaptação da levedura ou seleção de leveduras mais adaptadas ao meio fazem-se necessárias tendo em vista a produção de etanol a partir de resíduo amiláceo do processamento de mandioca.

\section{CONCLUSÕES}

A adição de melaço ao substrato amiláceo derivado da industrialização da mandioca em doses a partir de $10 \%$ levou a um aumento no teor de açúcares no mosto, promovendo uma maior produção de etanol cerca de $112 \%$ em relação à solução sem o aditivo. Contudo, a seleção de leveduras adaptadas ao substrato faz-se necessária para um melhor rendimento da produção de etanol.

\section{AGRADECIMENTOS}

Os autores agradecem às empresas, pela doação das matérias-primas e o CNPQ, pelo suporte financeiro.

\section{REFERÊNCIAS BIBLIOGRÁFICAS}

CABELLO, C. Identificação de parâmetros para monitoramento de processo contínuo de hidrólise enzimática, na produção de glicose a partir de fécula de mandioca. 1995. 208 f. Tese (Doutorado em Agronomia) Faculdade de Ciências Agronômicas, Universidade Estadual Paulista, Botucatu, 1995.

CAMPOS, H. Estatística aplicada à experimentação com cana-de-açúcar. Piracicaba: FEALQ, 1984. 297 p.

NAJAFPOUR, D. G.; SHAN-POI, C. Enzymatic hydrolisis of molasses. Bioresourse Technology, Essex, v. 86, p. 9194, 2003. 